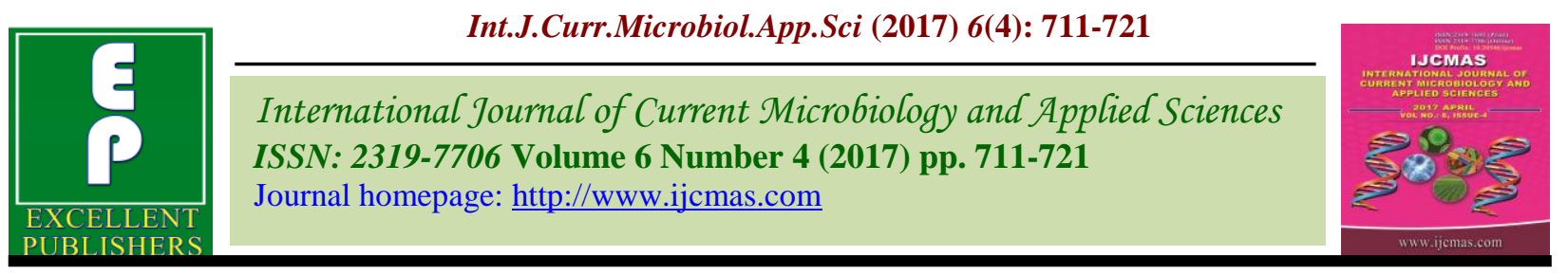

Original Research Article

https://doi.org/10.20546/ijcmas.2017.604.087

\title{
Distribution of Zinc Fractions and Its Association with Soil Properties in Some Rice-Wheat Growing Soils of Jammu Region, India
}

\author{
Enoch Spalbar*, Asim Kr. Mondal and A.P. Rai \\ Division of Soil Science and Agricultural Chemistry, FoA, SKUAST of Jammu, \\ Chatha, Jammu, J\&K, 180009, India \\ *Corresponding author
}

\begin{tabular}{|c|c|}
\hline & A B S T R A C T \\
\hline & \multirow{6}{*}{ 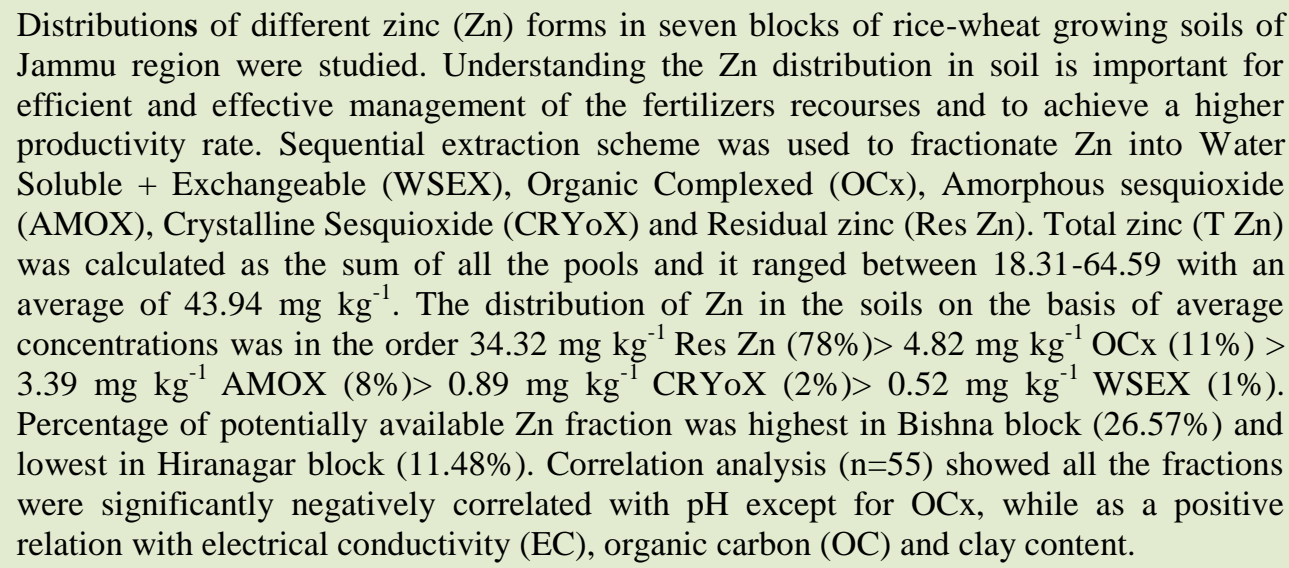 } \\
\hline & \\
\hline $\begin{array}{l}\text { Jammu, Zn fraction, } \\
\text { Rice-Wheat }\end{array}$ & \\
\hline Article Info & \\
\hline $\begin{array}{l}\text { Accepted: } \\
\text { 06 March } 2017 \\
\text { Available Online: } \\
10 \text { April } 2017\end{array}$ & \\
\hline & \\
\hline
\end{tabular}

\section{Introduction}

For an effective and efficient management of the fertilizer recourses, a deep understanding of the distribution of $\mathrm{Zn}$ fractions is important. Factors like parent material, pedochemical transformations and anthropogenic interventions contribute in the distribution of $\mathrm{Zn}$ and its bio availability for plant uptake (Chirwa and Yorokun, 2012). Zinc being a micronutrient is required in a very low quantity by the crops but never the less it is indispensible from a nutritional point of view and its deficiency can lead to several disorders in plants as it is associated with several enzymes. The soils of Jammu region where the rice-wheat growing pattern is practiced majorly and the rice grown in this area plays an important role in the economy of the state especially the aromatic variety of basmati (B-370) (Anonymous, 2015). The soils of J\&K suffer severely due to the intense soil erosion which is more than $20 \mathrm{t} \mathrm{ha}^{-1}$ each year (Singh et al., 1997). It causes a huge loss to the fertility and nutrient content of soil. The Zn content of Jammu soils range between 0.1$0.61 \mathrm{mg} \mathrm{kg}^{-1}$ and these soils have been reported deficient in $\mathrm{Zn}$ by various authors (Ali 2011; Mondal et al., 2006a; 2006b).

Availability of $\mathrm{Zn}$ for plants was reported to be associated with the distribution of this 
nutrient among soil fractions. Therefore understanding the distribution of $\mathrm{Zn}$ among various fractions of soil will help to characterize chemistry of $\mathrm{Zn}$ in soils and possibly its availability for plant uptake. However, distribution of $\mathrm{Zn}$ among various chemical forms may vary significantly in response to changing soil properties (Adhikari and Rattan, 2007). For a better understanding, total $\mathrm{Zn}$ can be broadly described in five mechanistic fractions which can be quantified using sequential or batch fractionation schemes (Saffari et al., 2009). Sequential fractionation quantifies the element distribution between fractions of different binding strength, as defined by properties of selected extractants. Viets (1962) defined five distinct pools for micronutrients. These are (i) water soluble (ii) exchangeable, (iii) adsorbed, complex and chelated species, (iv) associated with secondary minerals and insoluble metal oxides, and (v) associated with primary minerals. Zinc deficiency in soils suggests that both native and applied $\mathrm{Zn}$ react with the inorganic and organic phases in the soils, which influence plant-availability. Viets (1962) reported that the distribution of $\mathrm{Zn}$ among active and non-active soil constituents, and soil solution, was also fundamental to an understanding the chemistry of $\mathrm{Zn}$ in soil. These fractions give detailed information about the biological, geological and chemical processes occurring in the soil and give a detailed account of the available $\mathrm{Zn}$ for plants. Residual and oxide bound $\mathrm{Zn}$ is known to be more stable while as exchangeable and water soluble $\mathrm{Zn}$ fractions are more soluble (Rahmani et al., 2012). The extent to which each fraction is present and the transformations in equilibrium between fractions is influenced by soil properties such as $\mathrm{pH}$, texture and soil organic matter (Ramzan et al., 2014). Information and studies on $\mathrm{Zn}$ in these areas were limited only to DTPA extractable Zn. Zinc being an important micronutrient for rice and rice being an important crop in these areas, the present study was therefore aimed at obtaining a more detailed and critical information and understanding the transformations of soil $\mathrm{Zn}$ fractions and their Zn supply potential.

\section{Materials and Methods}

Seven blocks were selected from the ricewheat growing areas of Jammu region namely Kathua, Hiranagar, Samba, Vijaypur, Ghagwal, Bishna and R.S.Pura. Fifty five (55) composite surface soil samples were collected using global positioning system (GPS). The soils were analyzed for the various physico chemical properties following the standard procedures. Soil reaction $(\mathrm{pH})$ of the samples was measured in 1:2.5 soil: water suspension with a digital glass electrode $\mathrm{pH}$ meter (Jackson 1973). Electrical Conductivity (EC) was determined by method given by Richards (1954). Walkley and Black's (1934) rapid titration method was used for determination of organic carbon (OC). The mechanical analysis of the soil samples was done by following the international Pipette method as described by Piper (1966). The international society of soil science textural triangle was used for determining the textural class.

\section{Chemical fractionation of zinc}

The sequential extraction of soil $\mathrm{Zn}$ was carried out as per the procedure Murthy (1982) modified by Mandal and Mandal (1986).

Water soluble + exchangeable Zn (WSEX) was determined by taking $5 \mathrm{gm}$ soil samples in a $100 \mathrm{ml}$ polyethylene centrifuge tubes. 20 $\mathrm{ml}$ of $1 \mathrm{M} \mathrm{NH} \mathrm{NHAc}_{4}$ with $\mathrm{pH}$ maintained at 7.0 was shaken for 1 hour.

For Organically Complexed zinc (OCx) the residue of $1^{\text {st }}$ fraction was taken and $20 \mathrm{ml}$ of 
$0.05 \mathrm{M} \mathrm{Cu}(\mathrm{OAc})_{2}$ was added and it was shaken for 1 hour.

For Amorphous Sesquioxide bound Zn $(\mathrm{AMOX})$, the residue of $2^{\text {nd }}$ fraction was taken and it was acidified with $20 \mathrm{ml}$ of $0.2 \mathrm{M}$ $\mathrm{NH}_{4}(\mathrm{OX})_{2}$ with $\mathrm{pH}$ maintained at 3.0 and shaken for 1 hour.

For Crystalline Sesquioxide bound Zn (CRYoX), the residue of $3^{\text {rd }}$ fraction was taken and $40 \mathrm{ml} 0.3 \mathrm{M}$ sodium citrate $+5 \mathrm{ml}$ of $1.0 \mathrm{M} \mathrm{NaHCO} 3$ was added and it was stirred and kept in a water bath at temperature $70^{\circ}$ to $80^{\circ} \mathrm{C}$ for $10 \mathrm{~min}$ then $1 \mathrm{gm} \mathrm{Na}_{2} \mathrm{~S}_{2} \mathrm{O}_{4}$ was added and it was kept in a water bath at temperature $70^{\circ}$ to $80^{\circ} \mathrm{C}$ for $15 \mathrm{~min}$ with occasional stirring and it was cooled

Residual Zn (Res Zn) was extracted by digesting the residue of $4^{\text {rd }}$ fraction with a mixture of $5 \mathrm{ml}$ of concentrated $\mathrm{HNO}_{3}, 10 \mathrm{ml}$ of hydrofluoric acid and $10 \mathrm{ml}$ of perchloric acid, the cooled solution was transferred to a $50 \mathrm{ml}$ volumetric flask and subsequently diluted to volume with deionized water and stored for analysis.

Total $\mathrm{Zn}$ ( $\mathrm{T} \mathrm{Zn)} \mathrm{was} \mathrm{calculated} \mathrm{as} \mathrm{the} \mathrm{sum} \mathrm{of}$ all the fractions determined.

After each extraction the suspension was centrifuged at $4000 \mathrm{rpm}$ for 20 minutes. The solution was filtered with Whatman no 42 filter paper and the residue were used for the subsequent extractions. All extracts were analyzed for $\mathrm{Zn}$ by flame atomic adsorption spectrophotometer model Z.2300 (Hitachi, Japan).

\section{Results and Discussion}

\section{Physico- chemical properties of soil under study}

The various physico chemical properties of the rice-wheat growing soils of the Jammu region used in the study are given in Table- 1 . The studies revealed the value of $\mathrm{pH}$ for the soils ranged from between 6.10-7.68 with an average value of 6.92 . The soils exhibited near neutral to slightly alkaline reaction. The amount of O.C ranged between 3.20-7.80 with an average value of $5.73 \mathrm{~g} \mathrm{~kg}^{-1}$ respectively. Similar ranges of $\mathrm{pH}$ values and OC values have been reported by Jatav et al., (2007). The EC ranged between 0.14-0.67 with an average value of $5.73 \mathrm{dS} \mathrm{m}^{-1}$ with the soils being non saline in nature. The very low EC of soils can be attributed to the loss of soluble salts due to surface runoff during monsoon season because of undulating topography of the region (Jatav et al., 2007). The mechanical separate (sand, silt and clay) percentage of these soils revealed that the sand content ranged from 23.20-56.70 with an average value of $39.35 \%$. The silt content ranged between 14.00-38.40 with an average value of $27.39 \%$. The clay content ranged between 18.80-48.90 with an average value of $33.07 \%$. The divergent textural classes of the soils were noted from sandy clay loam (SCL) to clay loam (CL) and the majority of soil samples were clayey loam in texture. These results are in close agreement with Similar results were reported by Singh and Mishra (2012).

\section{Fractionation and distribution of zinc in soils under study}

The results of the different chemical fractions of $\mathrm{Zn}$ are presented in Table 2 and Fig 1. The evaluations of the $\mathrm{Zn}$ fractions in these soils revealed that the $\mathrm{Zn}$ were present in the following order Res $\mathrm{Zn}\left(34.32 \mathrm{mg} \mathrm{kg}^{-1}\right)>$ OCX (4.82 mg kg-1) > AMOX (3.39 $\mathrm{mg} \mathrm{kg}^{-1}$ ) $>$ CRYoX > $\left(0.89 \mathrm{mg} \mathrm{kg}^{-1}\right)>\operatorname{WESX}(0.52$ $\mathrm{mg} \mathrm{kg}^{-1}$ ).

The percentage of $\mathrm{Zn}$ fractions studied is given in Fig 2. WSEX was found to be the least fraction of $\mathrm{Zn}$ available with a range of 0.11- $0.99 \mathrm{mg} \mathrm{kg}^{-1}$. The percentage of WSEX 
forms of $\mathrm{Zn}$ was 1.0 percent among the entire $\mathrm{Zn}$ fractions studied this fraction of $\mathrm{Zn}$ was the least dominant fraction of $\mathrm{Zn}$. This might be due to high zinc buffering capacity of soils which resulted in low amount of WSEX Deb (1997). The WSEX was found to be least among $\mathrm{Zn}$ fractions as $\mathrm{Zn}$ in this form is mobile and readily available for biological uptake in the environment. Similar results were found by Kumar and Babel (2011) and Ramzan et al., (2014). The percentage of CRYoX forms of $\mathrm{Zn}$ was 2.0 percent among the entire $\mathrm{Zn}$ fractions studied. This fraction of $\mathrm{Zn}$ was present in a range of $0.06-1.86 \mathrm{mg}$ $\mathrm{kg}^{-1}$. This might be due to chemical affinity or specific adsorption and also due to predominance of crystalline iron oxide contents. Similar results obtained by Pal et al., (1997). This fraction is more stable particularly in upland condition of soil. The crystalline oxide exhibit defect structures in which $\mathrm{Zn}^{2+}$ is incorporated to compensate change in values, thereby $\mathrm{Zn}^{2+}$ gets bound or adsorbed Schwertmann et al., (1985). The percentage of AMOX forms of $\mathrm{Zn}$ was 8.0 percent among the entire $\mathrm{Zn}$ fractions studied. This fraction of $\mathrm{Zn}$ was present in a range of 1.14-9.74 $\mathrm{mg} \mathrm{kg}^{-1}$. This may be attributed to greater ability of amorphous sesquioxide to adsorb $\mathrm{Zn}$ because of their high specific surface area, Devis and Leckie (1978). Water logging causes an increase in the AMOX forms of native soil $\mathrm{Zn}$ with a constant decrease in other forms, suggesting equilibrium of this form in soil (Mandal and Mandal, 1986). Similar results were observed by Tehrani (2005); Bahera et al., (2008) and Safari et al., (2009). Among the non residual fractions the OCx bound fraction was found to be the major fraction of $\mathrm{Zn}$ present. The percentage of OCx forms of $\mathrm{Zn}$ was 11.0 percent among the entire $\mathrm{Zn}$ fractions studied. This fraction of $\mathrm{Zn}$ was present in a range of $1.20-9.00 \mathrm{mg} \mathrm{kg}^{-1}$.It is known to play a significant role in $\mathrm{Zn}$ nutrition of lowland rice and water logging causes an increase in the
OCx forms of native soil $\mathrm{Zn}$ with a constant decrease in other forms, suggesting equilibrium of this form in soil Mandal and Mandal (1986). Similar values of organically complexed $\mathrm{Zn}$ have been reported by Prasad and Shukla (1996). The OCx fraction of $\mathrm{Zn}$ varied directly with the organic carbon content of the soils Mandal and Mandal (1986). Similar results were also reported by Tehrani (2005); Bahera et al., (2008); Safari et al., (2009) and Ramzan et al., (2014). The concentration of $\mathrm{Zn}$ in residual fraction varied between $15.26-49.12 \mathrm{mg} \mathrm{kg}^{-1}$. Major portion of the total $\mathrm{Zn}$ constituted of this fraction and its concentration in greater availability indicated its likely hood to be in non labile form. This being the residual fraction represents metals which are largely embedded in sedimentary matrix and might not be available for remobilization except under very extreme conditions (Mao and Rao, 1997). Similar results of residual $\mathrm{Zn}$ consisting of large proportions of total $\mathrm{Zn}$ was also reported by Singh, (2011) and Kamali et al., (2010).

\section{Mobility factor of zinc in soils under study}

The most mobile and bio-available factors of $\mathrm{Zn}$ are extracted early by any sequential extraction procedure. The mobility factor value determines the $\mathrm{Zn}$ present in mobile form or those which are biologically available to the plants. On this basis high mobility factor (MF) values have been reported or interpreted as evidence of relatively high reactivity, high liability and high biological availability of heavy metals in soil (Kabala and Singh, 2001; Ramzan et al., 2014). The mobility of the metals in the soil may be evaluated on the basis of absolute and relative contents of fractions weakly bound to soil components. The relative index of metal mobility has been calculated as a mobility factor using sequential extraction scheme (Narwal et al., 1999; Ramzan et al., 2014). Mobility factor was calculated as the sum of 
all the mobile fractions of $\mathrm{Zn}$ which were WSEX, OCX, AMOX and CRYoX fractions of Zn (Tessier et al., 1979; Kabala and Singh, 2001). The mobility factor percentage was observed to be maximum in Bishna (26.57) $>$ R.S.Pura (22.72)> Ghagwal (22.60) Kathua (20.47) > Vijaypur (17.97) >Samba (16.11) and Hiranagar (11.48) Fig 3, low levels of labile or bio available $\mathrm{Zn}$ has been attributed to the low levels of native $\mathrm{Zn}$, slow solubilization $\mathrm{Zn}$ in soil, strong adsorption of $\mathrm{Zn}$ and leaching of $\mathrm{Zn}$ dissolved with $\mathrm{OM}$ (Rieuwerts et al., 2006).

Table.1 Physico-chemical characteristics of rice-wheat growing soils of Jammu region

\begin{tabular}{|c|c|c|c|c|c|c|c|c|}
\hline Block & & $\begin{array}{l}\text { pH } \\
(1: 2.5)\end{array}$ & $\begin{array}{l}\text { EC } \\
\left(\mathrm{dSm}^{-1}\right)\end{array}$ & $\begin{array}{l}\text { OC } \\
\left(\mathrm{g} \mathrm{kg}^{-1}\right)\end{array}$ & $\begin{array}{l}\text { Sand } \\
\%\end{array}$ & $\begin{array}{c}\text { Silt } \\
\%\end{array}$ & $\begin{array}{l}\text { Clay } \\
\%\end{array}$ & $\begin{array}{l}\text { Textural } \\
\text { Class }\end{array}$ \\
\hline \multirow[t]{3}{*}{ Kathua } & Range & $6.25-7.16$ & $0.22-0.35$ & $4.60-7.80$ & $35.60-$ & $22.00-$ & $29.00-$ & Clay \\
\hline & Mean & 6.76 & 0.31 & 6.71 & 47.10 & 32.00 & 39.30 & loam \\
\hline & & & & & 39.27 & 28.10 & 32.55 & \\
\hline \multirow[t]{3}{*}{ Hiranagar } & Range & 7.29-7.50 & $0.27-0.36$ & $3.70-4.60$ & $25.10-$ & $26.00-$ & $18.80-$ & Clay \\
\hline & Mean & 7,40 & 0.31 & 4.22 & 49.20 & 32.00 & 48.90 & loam \\
\hline & & & & & 37.90 & 29.36 & 32.74 & \\
\hline \multirow[t]{3}{*}{ Samba } & Range & $7.40-7.44$ & $0.14-0.41$ & $3.20-4.70$ & $33.80-$ & $18.20-$ & $18.80-$ & Clay \\
\hline & Mean & 7.41 & 0.34 & 4.00 & 49.00 & 32.50 & 48.00 & loam \\
\hline & & & & & 39.40 & 28.30 & 32.26 & \\
\hline \multirow[t]{3}{*}{ Vijaypur } & Range & $6.33-7.68$ & $0.21-0.38$ & $3.40-7.30$ & $27.10-$ & $22.10-$ & $26.10-$ & Clay \\
\hline & Mean & 6.88 & 0.30 & 5.90 & 46.50 & 30.60 & 42.30 & loam \\
\hline & & & & & 40.72 & 28.10 & 31.18 & \\
\hline \multirow[t]{3}{*}{ Ghagwal } & Range & $6.10-6.58$ & $0.25-0.38$ & $6.00-7.60$ & $26.50-$ & $24.00-$ & $24.10-$ & Clay \\
\hline & Mean & 6.31 & 0.33 & 6.76 & 44.80 & 30.10 & 43.70 & loam \\
\hline & & & & & 35.26 & 28.40 & 36.34 & \\
\hline \multirow[t]{3}{*}{ Bishna } & Range & $6.33-7.34$ & $0.22-0.47$ & $3.90-7.40$ & $23.20-$ & $14.00-$ & 29.70- & Clay \\
\hline & Mean & 6.71 & 0.35 & 6.20 & 56.30 & 38.40 & 48.80 & loam \\
\hline & & & & & 35.38 & 27.35 & 36.28 & \\
\hline \multirow[t]{3}{*}{ R.S.Pura } & Range & $6.22-7.55$ & $0.28-0.67$ & $3.50-7.70$ & $26.30-$ & $14.00-$ & $27.70-$ & Clay \\
\hline & Mean & 6.89 & 0.39 & 6.14 & 56.70 & 34.20 & 39.80 & loam \\
\hline & & & & & 42.49 & 24.96 & 32.28 & \\
\hline
\end{tabular}


Table.2 Chemical speciation of zinc $\left(\mathrm{mg} \mathrm{kg}^{-1}\right)$ in rice-wheat growing soils of Jammu region

\begin{tabular}{|c|c|c|c|c|c|c|c|}
\hline Block & & OCx & CRYoX & AMOX & WSEX & Res Zn & T Zn \\
\hline \multirow[t]{2}{*}{ Kathua } & Range & $1.20-3.90$ & $0.52-0.92$ & $1.73-4.64$ & $0.13-0.39$ & $24.75-31.80$ & $28.41-40.71$ \\
\hline & Mean & 2.98 & 0.79 & 3.37 & 0.32 & 28.94 & 36.39 \\
\hline \multirow[t]{2}{*}{ Hiranagar } & Range & $1.30-1.70$ & $0.46-0.66$ & $1.14-1.88$ & $0.11-0.17$ & $24.88-34.03$ & $28.51-37.85$ \\
\hline & Mean & 1.56 & 0.55 & 1.50 & 0.13 & 28.81 & 32.55 \\
\hline \multirow[t]{2}{*}{ Samba } & Range & $1.30-2.10$ & $0.22-0.66$ & $1.14-1.71$ & $0.17-0.36$ & $19.33-21.71$ & $22.88-25.75$ \\
\hline & Mean & 1.74 & 0.46 & 1.50 & 0.23 & 20.42 & 24.34 \\
\hline \multirow[t]{2}{*}{ Vijaypur } & Range & $1.20-2.80$ & $0.42-0.96$ & $1.25-2.88$ & $0.18-0.86$ & $15.26-33.75$ & $18.31-40.99$ \\
\hline & Mean & 2.26 & 0.79 & 2.31 & 0.67 & 27.56 & 33.60 \\
\hline \multirow[t]{2}{*}{ Ghagwal } & Range & $2.50-3.50$ & $0.77-0.93$ & $2.41-4.25$ & $0.71-0.91$ & $26.07-28.53$ & $34.49-37.22$ \\
\hline & Mean & 2.98 & 0.89 & 3.39 & 0.82 & 27.69 & 35.77 \\
\hline \multirow[t]{2}{*}{ Bishna } & Range & $1.80-9.00$ & $0.25-1.86$ & $1.49-9.74$ & $0.16-0.98$ & $41.62-46.07$ & $54.14-64.21$ \\
\hline & Mean & 6.10 & 1.24 & 5.06 & 0.69 & 43.35 & 59.04 \\
\hline \multirow[t]{2}{*}{ R.S.Pura } & Range & $2.40-8.40$ & $0.06-1.86$ & $1.19-4.65$ & $0.19-0.99$ & $33.44-49.12$ & $43.97-64.59$ \\
\hline & Mean & 5.43 & 1.02 & 3.10 & 0.63 & 42.81 & 55.40 \\
\hline
\end{tabular}

OCx: - Organically Complex, AMOX:-Amorphous Sesquioxide Bound Form, CRYoX:-Crystalline Sesquioxide, WSEX:-Water Soluble Oxide, Res Zn- Residual Zinc, T Zn- Total Zinc

Table.3 Correlation coefficients between different chemical fractions of $\mathrm{Zn}$ and soil Physicochemical properties

\begin{tabular}{lcccccc}
\hline & OCx & CRYoX & AMOX & WSEX & Res Zn & T Zn \\
\hline pH & -0.185 & $-0.617^{* *}$ & $-0.481^{* *}$ & $-0.724^{* *}$ & $-0.343^{*}$ & $-0.385^{* *}$ \\
EC & $0.345^{* *}$ & 0.138 & 0.056 & 0.120 & 0.264 & $0.270^{*}$ \\
OC & 0.230 & $0.329^{*}$ & 0.164 & $0.422^{* *}$ & 0.200 & 0.232 \\
Sand & 0.023 & -0.239 & -0.152 & -0.164 & -0.061 & -0.072 \\
Silt & -0.237 & 0.047 & -0.084 & -0.126 & -0.184 & -0.191 \\
Clay & 0.134 & 0.239 & 0.222 & $0.268^{*}$ & 0.188 & 0.205 \\
* significant at 0.05 level, **= significant at 0.01 level & &
\end{tabular}

OCx: - Organically Complex, AMOX:-Amorphous Sesquioxide Bound Form, CRYoX:-Crystalline Sesquioxide, WSEX:-Water Soluble Oxide, Res Zn- Residual Zinc, T Zn- Total Zinc 
Table.4 Linear regression equation showing the combined influence of soil properties on different forms of soil $\mathrm{Zn}$ fractions

\begin{tabular}{|c|c|c|}
\hline & Equation & $\mathbf{R}^{2}$ \\
\hline \multirow[t]{2}{*}{1} & $\mathbf{O C x}$ & \\
\hline & $Y=46.53+0.190\left(X_{1}\right)+7.939\left(X_{2}\right)+0.488\left(X_{3}\right)-0.476\left(X_{4}\right)-0.545\left(X_{5}\right)-0.446\left(X_{6}\right)$ & $0.205^{*}$ \\
\hline \multirow[t]{2}{*}{2} & CRYoX & \\
\hline & $Y=3.307-0.464\left(X_{1}\right)+0.496\left(X_{2}\right)+0.021\left(X_{3}\right)-0.001\left(X_{4}\right)-0.012\left(X_{5}\right)-0.008\left(X_{6}\right)$ & $0.414 * *$ \\
\hline \multirow[t]{2}{*}{3} & AMOX & \\
\hline & $Y=46.38-1.857\left(X_{1}\right)-1.180\left(X_{2}\right)-0.044\left(X_{3}\right)-0.305\left(X_{4}\right)-0.324\left(X_{5}\right)-0.291\left(X_{6}\right)$ & $0.270^{*}$ \\
\hline \multirow[t]{2}{*}{4} & WSEX & \\
\hline & $Y=7.353-0.359\left(X_{1}\right)-0.147\left(X_{2}\right)+0.040\left(X_{3}\right)-0.049\left(X_{4}\right)-0.049\left(X_{5}\right)-0.044\left(X_{6}\right)$ & $0.570 * *$ \\
\hline \multirow[t]{2}{*}{5} & Res Zn & \\
\hline & $Y=208.9-3.530\left(X_{1}\right)+17.631\left(X_{2}\right)+0.715\left(X_{3}\right)-1.629\left(X_{4}\right)-1.735\left(X_{5}\right)-1.535\left(X_{6}\right)$ & $0.203^{*}$ \\
\hline \multicolumn{3}{|c|}{$*=$ significant at 0.05 level, $* *=$ significant at 0.01 level } \\
\hline \multicolumn{3}{|c|}{$\mathbf{X}_{1}-\mathrm{pH}, \mathbf{X}_{2}-\mathrm{EC}, \mathbf{X}_{3}-\mathrm{OC}, \mathbf{X}_{4}$-Sand, $\mathbf{X}_{5}-$ Silt, $\mathbf{X}_{6}$-Clay } \\
\hline
\end{tabular}

Fig.1 Distribution of $\mathrm{Zn}$ fractions in study area

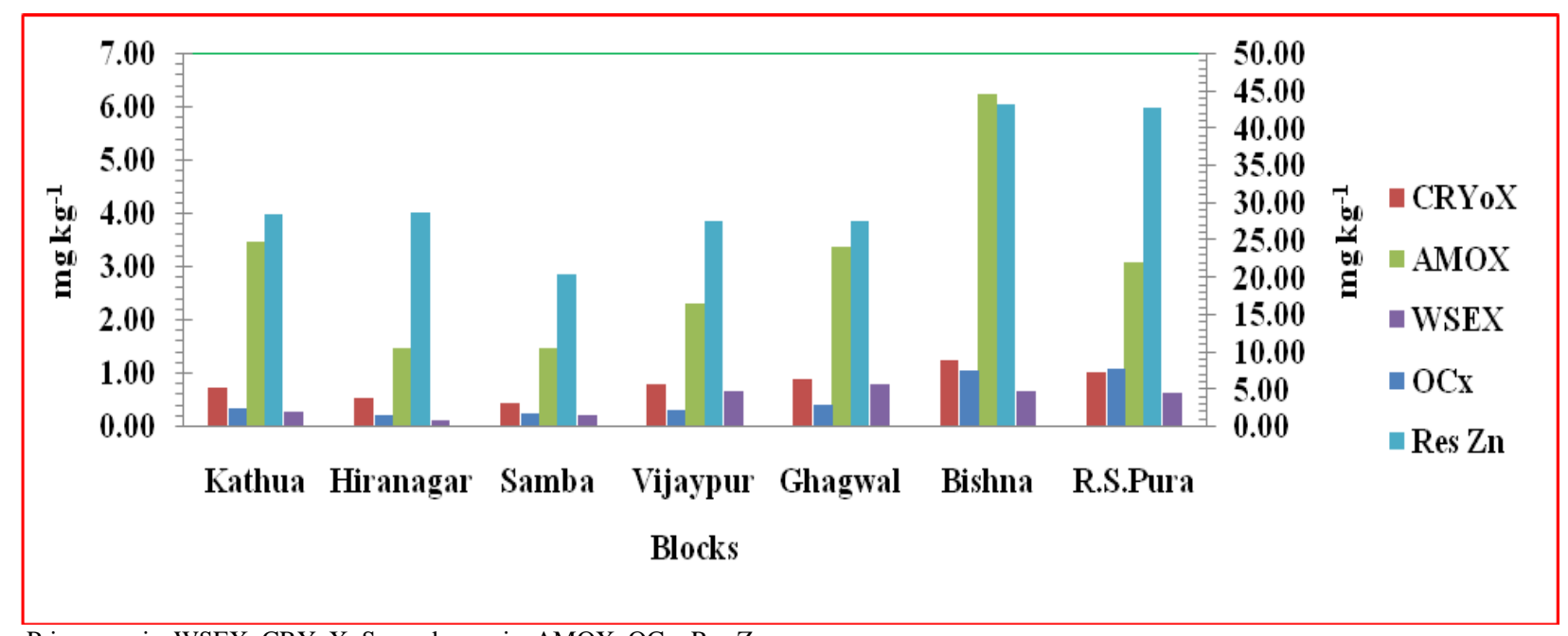

Primary axis: WSEX, CRYoX. Secondary axis: AMOX, OCx, Res Zn 
Fig.2 Pie chart of percentage of $\mathrm{Zn}$ fractions present in soil sample studied

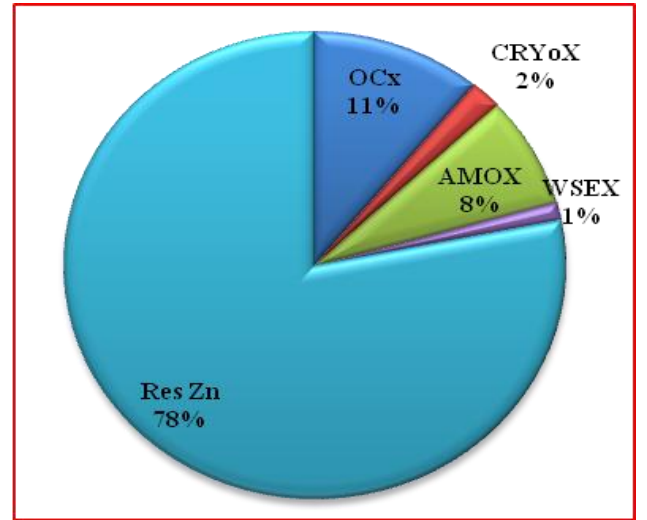

Fig.3 Available and non available concentrations of $\mathrm{Zn}$ fractions present in the study areas

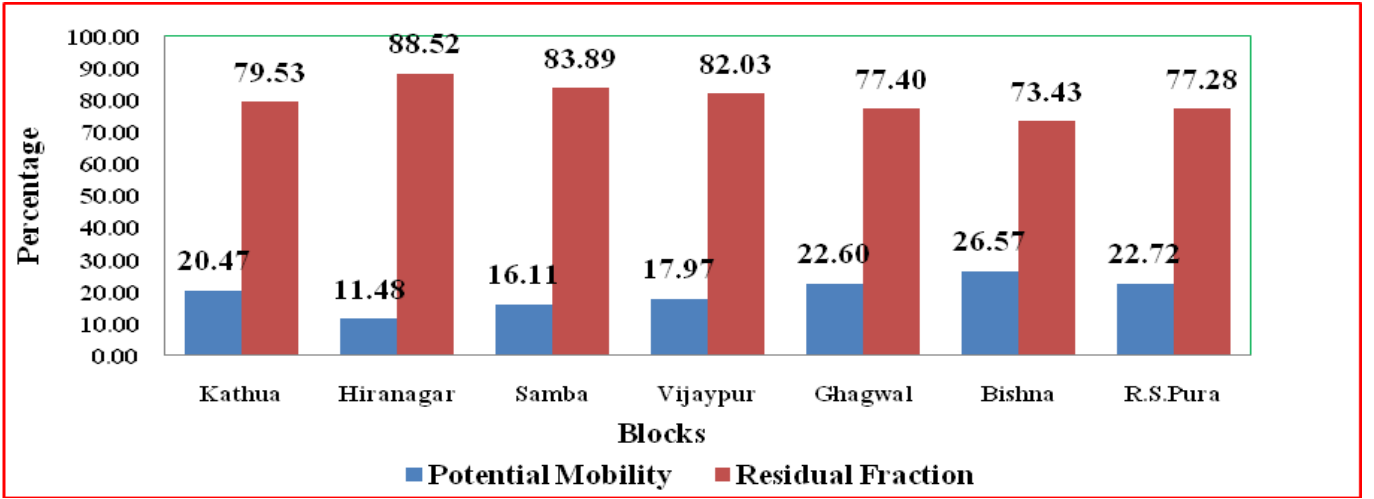

Relation between soil physico-chemical properties and zinc fractions

Bioavailability of nutrients contribute to the optimum growth of plants which in turn effect the crop productivity and the bioavailability of nutrients are greatly influenced by various soil physico-chemical properties like $\mathrm{pH}, \mathrm{EC}$, OM, adsorptive surfaces and various other physical and biological conditions in the rhizosphere (Bell and Dell, 2008; Wijebandara et al., 2011). Change in soil properties contribute in the distribution and availability of $\mathrm{Zn}$ in various chemical forms in the soil (Adhikari and Rattan, 2007). Soils which are generally heavy textured, lower $\mathrm{pH}$ and higher OM content can generally provide a greater reserve of these elements whereas, coarse textured soils such as sand have fewer reserves and tend to get depleted rather quickly (Yadav and Meena, 2009).

OCx bound $\mathrm{Zn}$ had a negative but no significant with $\mathrm{pH}(-0.185)$, a positive and significant with EC $\left(0.345^{* *}\right)$, with $\mathrm{OC}$ (0.230), sand (0.023) and Clay (0.134) it showed a positive and with Silt $(-0.237)$ a negative but no significant relationship. Organic acids and other functional groups in organic matter provides exchange sites for the adsorption of $\mathrm{Zn}$. Regression equation (1) (Table 4) showed that $20 \%$ variation in OCX bound $\mathrm{Zn}$ was due to soil properties studied and significant effects were in relation to EC (Shiowatana et al., 2005; Chirwa and Yerokun, 2012 and Ramzan et al., 2014) reported similar results in their studies. 
CRYoX bound $\mathrm{Zn}$ showed a negative and significant relationship with $\mathrm{pH}(-0.617 * *)$, with EC (0.138) a positive but no significant and with OC $\left(0.329^{*}\right)$ a positive and significant was observed. A negative and non significant with Sand (-0.239) and a positive but no significant relationship with Silt (0.047) and Clay (0.239) was observed. Regression equation (2) (Table 4) showed that $41 \%$ variation in CRYoX bound $\mathrm{Zn}$ was due to soil properties studied and significant effects were in relation to $\mathrm{pH}$ and $\mathrm{OC}$ (Shiowatana et al., 2005; Chirwa and Yerokun, 2012; Ramzan et al., 2014 and Meki et al., 2012) reported similar results in their studies.

AMOX bound $\mathrm{Zn}$ showed a negative and significant relationship with $\mathrm{pH}\left(-0.481^{* *}\right)$ was observed a reduction in AMOX fraction $\mathrm{Zn}$ with increase in $\mathrm{pH}$ can be explained by the natural reduction in oxide solubility and concentration as $\mathrm{pH}$ increases (Shiowatana et al., 2005 and Ramzan et al., 2014). While as a positive but no significant relationship between EC (0.056) and OC (0.16) was observed. A negative but no significant relationship was observed with Sand (-0.152) and Silt (-0.084) and a positive but no significant relationship was observed with Clay (0.222). Regression equation (3) (Table 4) showed that $27 \%$ variation in AMOX bound $\mathrm{Zn}$ was due to soil properties studied and significant effects were in relation to $\mathrm{pH}$ (Shiowatana et al., 2005; Chirwa and Yerokun, 2012; Ramzan et al., 2014 and Ashraf et al., 2012) reported similar results in their studies.

WSEX bound $\mathrm{Zn}$ showed a negative and significant relationship with soil $\mathrm{pH}$ ($0.724 * *)$ was observed. While as a positive but no significant was observed with EC (0.120) and positive and significant relationship was observed with OC $(0.422 * *)$, while as a negative but no significant relationship was observed with Sand (-0.164) and Silt (-0.126) and a positive and significant relationship was observed with Clay $\left(0.268^{*}\right)$. Regression equation (4) (Table 4) showed that $57 \%$ variation in WSEX bound $\mathrm{Zn}$ was due to soil properties studied and significant effects were in relation to $\mathrm{pH}, \mathrm{OC}$ and Clay (Chirwa and Yerokun, 2012; Ramzan et al., 2014 and Ibrahim et al., 2011) reported similar results in their studies.

Res $\mathrm{Zn}$ had a negative and significant relationship with soil $\mathrm{pH}\left(-0.343^{*}\right)$ while as a positive but no significant relationship was observed with EC (0.264) and OC (0.200) and Clay (0.188) while as a negative but no significant was observed with Sand (-0.061) and Silt (-0.184). Regression equation (5) (Table 4) showed that $20 \%$ variation in Res $\mathrm{Zn}$ bound $\mathrm{Zn}$ was due to soil properties studied and significant effects were in relation to $\mathrm{pH}$ (Chirwa and Yerokun, 2012 and Ramzan et al.,2014).

\section{References}

Adhikari, T. and Rattan, R.K. 2007. Distribution of zinc fractions in some major soils of India and the impact on nutrition of rice. Communications in Soil Science and Plant Analysis, 38: 2779-2798

Ali,A. 2011. Submergence effect on micronutrient availability in basmati growing soils of Jammu. MSc. Thesis. SKUAST-Jammu.

Anonymous. 2015. State of Indian Agriculture 2014-2015, GoI, Ministry of Agriculture.

Ashraf, M.A., Maah, M.J., Yuso, I. 2012. Chemical Speciation and potential mobility of heavy metals in the soil of former tin mining catchment. The Scientific World Journal, 10: 1-11.

Bahera, K,S., Singh, D., Dwivedi, B.S., Singh, S., Kumar, K. and Rana, D.S. 2008. Distribution of fractions of zinc and their contribution towards availability and plant uptake of zinc under long term 
maize and wheat cropping system on an inceptisols. Australian journal of soil recourses, 46:83-89.

Bell, R.W., Dell, B. 2008. Micronutrients for Sustainable Food, Feed, Fibre and Bioenergy Production. $1^{\text {st }}$ edition, IFA, Paris, France.

Chirwa, M. and Yerokun, O.A. 2012. The distribution of $\mathrm{Zn}$ fractions in surface samples of selected agricultural soils of Zambia. International journal of soil science, 7 (2): 51-60.

Deb, D. L., 1997, Micronutrient research and crop production in India. Journal of Indian Society of Soil Science, 45(4): 675-692.

Devis, J.A. and Leckie, J.O, 1978, Effect of adsorbed complexing legands on trace metal uptake by hydrous oxides. Environmental Science and Technology, 12: $1309-1315$.

Ibrahim, A.K., Usman, A., Abubakar, B., Aminu, U.H. 2011. Extractable micronutrients status in relation to other soil properties in Billiri Local Government Area. Journal of Soil Science and Environmental Management, 3: 282-285.

Jackson, M. L. 1973. Soil chemical analysis: Advanced course. The author, Madison, Wisconsin, USA.

Jatav, M.K., Sud, K.C. and Dua, V.K. 2007, Nutrient status of soils from high hills of potato growing areas of Shimla. Potato Journal, 34 (3 - 4): 216-220

Kabala, C. Singh, B.R. 2001. Fractionation and mobility of copper, lead and zinc in soil profiles in the vicinity of a copper smelter. Journal of Environmental Quality, 30: 485- 495.

Kamali, S. Ronaghi, A. and Karimian, N. 2010. Zinc transformation in a calcareous soil as affected by applied zinc sulfate, vermicompost and incubation time. Communications in Soil Science and Plant Analysis, 41:2318-2329.

Kumar, M. and Babel, A,L. 2011. Available micronutrient status and their relationship with soil properties of
Jhunjhunu Tehsil, District Jhunjhunu, Rajasthan. India Journal of Agricultural Sciences, 3:20 - 31.

Ma, L.Q. and Rao, N. 1997. Chemical fractionation of cadmium, copper, nickel and zinc in contaminated soils. Journal of Environmental Quality, 26: 259-264.

Mandal, L.N. and Mandal, B. 1986. Zinc fractions in soils in relation to zinc nutrition of lowland rice. Soil Science, 142: 141-148

Meki, C., Olusegun, A. and Yerokun. 2012. The distribution of Zinc fractions in surface samples of selected agricultural soils of Zambia. International Journal of Soil Science, 7: 51-60.

Mondal, A.K, Jalali, V.K, Sharma, V. 2006b. Distribution of Boron and primary micronutrients in orchids soils of temperate Jammu. Environ. Ecol., 24S (3): 611-613

Mondal, A.K., Sharma, V., Jalali, V.K., Arora, S., Wali, P. and Kher, D. 2006a. Distribution and relationship of macro and micronutrients in soils of Chattha the newly established location of SKUAST of Jammu. Journal of research, SKUAST-J. 6(2):234-242.

Murthy, A.S.P. 1982. Zn fraction in wetland rice soils and their availability to rice. Soil Science, 133(3):150-154.

Narwal, R.P., Singh, B.R. 1999. Sorption of cadmium, zinc, copper and lead by soils developed on alun shales and other materials. Norwegian Journal of Agricultural Science. 9:(3-4)177.

Pal, A.K., Das, P.R., Patnaik, S.K. and Mandal, B., 1997, Zinc fractions in some rice growing soils of Orissa. Journal of the Indian society of soil science, 45:734738.

Piper, C.S. 1966. Soil and Plant Analysis, Hans Publisher. Bombay, India

Prasad, and Shukla, L.M. 1996. Forms of zinc and their relationship with soil properties. Journal of the Indian society of soil science, 44(3):516-518.

Rahmani, B., Tehrani, M.M., Khanmirzaei A., 
Shahbazi, K. 2012. Cadmium fractions and its uptake by the wheat plant in some calcareous soils of Iran. International Journal of Agriculture Research and Review, 2: 461-466.

Ramzan, S., Bhat, M. A., Kirmani, N.A. and Rasool, R. 2014. Fractionation of zinc and their association with soil properties in soils of Kashmir Himalayas. International Journal of Agricultural and Soil Science, 2(8):132-142.

Rieuwerts, J.S., Ashmore, M.R,. Farago, M.E. and Thornton, I. 2006. The influence of soil characteristics on the extractability of $\mathrm{Cd}, \mathrm{Pb}$ and $\mathrm{Zn}$ in upland and moorland soils. Science of Total Environment, 366: 864-875.

Safari, M., Yasrebi, J., Karimian, N. and Shan, X.Q. 2009. Evaluation of three sesquential extraction methods for fractionation of zinc in calcerious and acidic soils. Resources of Biology science, 4:848-857.

Schwertman, U., Cambier, P.H. and Murad,E., 1985, Properties of goethites of varying crystallinity. Clays and Clay Minerals, 33: 369-378.

Shiowatana, J. Buanuam, J. Pongsakul, P. 2005. Fractionation and elemental association of $\mathrm{Zn}, \mathrm{Cd}$ and $\mathrm{Pb}$ in soils contaminated by $\mathrm{Zn}$ mining's using a continuous flow sequential extraction. Journal of Environment Monitoring, 7: 778-784.

Singh, G., Babu, R., Narain, P., Bhushan, L. S. and Abrol, I. P. 1997. Soil erosion rates in India. Journal of Soil and Water Conversation, 47(1): 97-99.

Singh, M.V. 2011. Assessing extent of zinc deficiency for soil factors affecting and nutritional scarcity in humans and animals. Indian Journal of Fertilizers,
7(10):36-43.

Singh, R.P. and Mishra, S.K. 2012. Available macronutrients $(\mathrm{N}, \mathrm{P}, \mathrm{K}$ and $\mathrm{S})$ in the soils of Chiraigaon block of district Varanasi (U.P.) in relation to soil characteristics. Indian Journal of Soil Research, 3(1):97-100.

Tehrani, M.M. 2005. Zinc mobility and its distribution among different pools in soil. Geophys. Res. Abst. 7:1056110561.

Tessier, A., Cambell, P.G.C. and Bisson, M. 1979. Sequential extraction procedure for specification of particulate trace metals. Analytical Chemistry, 51:844851.

Viets, F.G.Jr. 1962. Chemistry and availability of micronutrients in soils. Journal of Agricultural Food Chemistry, 10:174178.

Walkey, A. and Black, I.A. 1934. An experimentation of the Degtjareff method for determining soil organic matter, and proposed modification of the chromic acid titration method. Soil Science, 37:29-38.

Wijebandara, D.M.D.I., Dasong, G.S and Patil, P.L. 2011. Zinc fractions and their relationship with soil properties in Paddy growing soils of northern dry hill zones of Karnataka. Journal of the Indian Society of Soil Science, 59:141147.

Yadav, R.L. and Meena, M.C. 2009. Available micronutrient status and their relationship with soil properties of Degana soil series of Rajasthan. Journal of the Indian Society of Soil Science 57, 90-92.

\section{How to cite this article:}

Enoch Spalbar, Asim Kr. Mondal, Rai, A.P. 2017. Distribution of Zinc Fractions and Its Association with Soil Properties in Some Rice-Wheat Growing Soils of Jammu Region. Int.J.Curr.Microbiol.App.Sci. 6(4): 711-721. doi: https://doi.org/10.20546/ijcmas.2017.604.087 